\title{
Estela con iconografía e inscripción celtibéricas procedente de Clunia*
}

\section{Stele with Celtiberian iconography and inscription from Clunia}

\author{
Ignacio Simón Cornago ${ }^{1}$ \\ Departamento de Estudios Clásicos, Universidad del País Vasco / Euskal Herriko Unibertsitatea \\ Joaquín Gorrochategui ${ }^{2}$ \\ Instituto de Ciencias de la Antigüedad, Universidad del País Vasco / Euskal Herriko Unibertsitatea
}

\section{RESUMEN}

El objetivo del trabajo es publicar una nueva estela celtibérica recuperada en Clunia. Es una pieza que contiene una inscripción celtibérica y la representación de un guerrero, combinación característica de los monumentos procedentes de esta ciudad. El texto está inscrito en signario celtibérico occidental, presenta redundancia vocálica $y$, en principio, es compatible con el denominado sistema dual. Se dispone en una única línea de texto delimitada por dos líneas incisas, quizá parte de una cartela. La lectura propuesta es mukuuroskiimine $+\mathrm{y}$, aunque no hay interpunciones, lo más plausible es identificar en primero término un nombre personal (Muguros) y un segundo elemento que carece de buenos paralelos. Sobre el epígrafe aparece un infante calzado con botas, pertrechado con grebas y que parece vestir un sagum, con su diestra agarra un astil que porta sobre el hombro y cuyo extremo superior se ha perdido.

\section{SUMMARY}

The goal of the paper is to publish a new Celtiberian stele recovered in Clunia. It is a piece which contains a Celtiberian inscription and the representation of a warrior, a characteristic combination of monuments originating in this city. The text is written in Western Celtiberian script, presenting vowel redundancy and, in principle, it is compatible with the so-called dual system of writing. It contains one single line of text delimited by two lines, perhaps part of a cartouche. The proposed interpretation is mukuuroskiimine+ and, while there are no interpuncts, it is initially most plausible to identify a personal name (Muguros) and a second element which lacks any good parallels. Above the epigraph there is an infantryman, wearing boots, equipped

\footnotetext{
* Este trabajo se incluye en el proyecto de investigación: Hesperia: lenguas, epigrafía y onomástica paleohispánica (FFI2015-63981-C3-1-P) financiado por el Ministerio de Economía y Competitividad del Gobierno de España (MINECO) y el Fondo Europeo de Desarrollo Regional (FEDER).

${ }^{1}$ isimoncornago@gmail.com / ORCID iD: https://orcid. org/0000-0001-5995-9599.

2 joaquin.gorrochategui@ehu.eus / ORCID iD: https://orcid. org/0000-0001-5433-2156.
}

with greaves and who appears to be dressed in a sagum; in his right hand he is holding a shaft which he is carrying over his shoulder and whose upper end has been lost.

PALABRAS CLAVE: celtibérico; guerrero celtibérico; grebas; sistema dual.

KEY WORDS: Celtiberian language; Celtiberian warrior; greaves; dual system of writing.

CÓMO CITAR ESTE ARTÍCULO / CITATION: Simón Cornago, I. y Gorrochategui, J. 2018: "Estela con iconografía e inscripción celtibéricas procedente de Clunia". Archivo Español de Arqueología 91: 55-66. https://doi.org/10.3989/ aespa.091.018.003

\section{HALLAZGO DE LA ESTELA}

Según consta a los responsables de las excavaciones en Clunia, la inscripción fue hallada en Abril de 2010. El guarda del yacimiento la recuperó en la linde de un camino junto al pueblo de Peñalba de Castro y actualmente se conserva en los almacenes del Centro de Interpretación de Clunia. Nos informó de su existencia Adelaida Rodríguez, conservadora del Museo Provincial de Burgos, y la autopsia fue realizada el día 28 de julio de 2015 y de nuevo el 23 de marzo de 2016, gracias a la amable colaboración del Dr. Francesc Tuset, director de las excavaciones, y de Gerardo Martínez.

Se trata de una pieza realizada en caliza e incompleta en sus extremos inferior y superior. Conserva los lados originales, cuyas aristas están biseladas; sus dimensiones son (62) $\mathrm{cm}$ de altura, $63 \mathrm{~cm}$ de anchura y $23 \mathrm{~cm}$ de grosor (Fig. 1). Presumiblemente es parte de una estela de formato rectangular, pues 


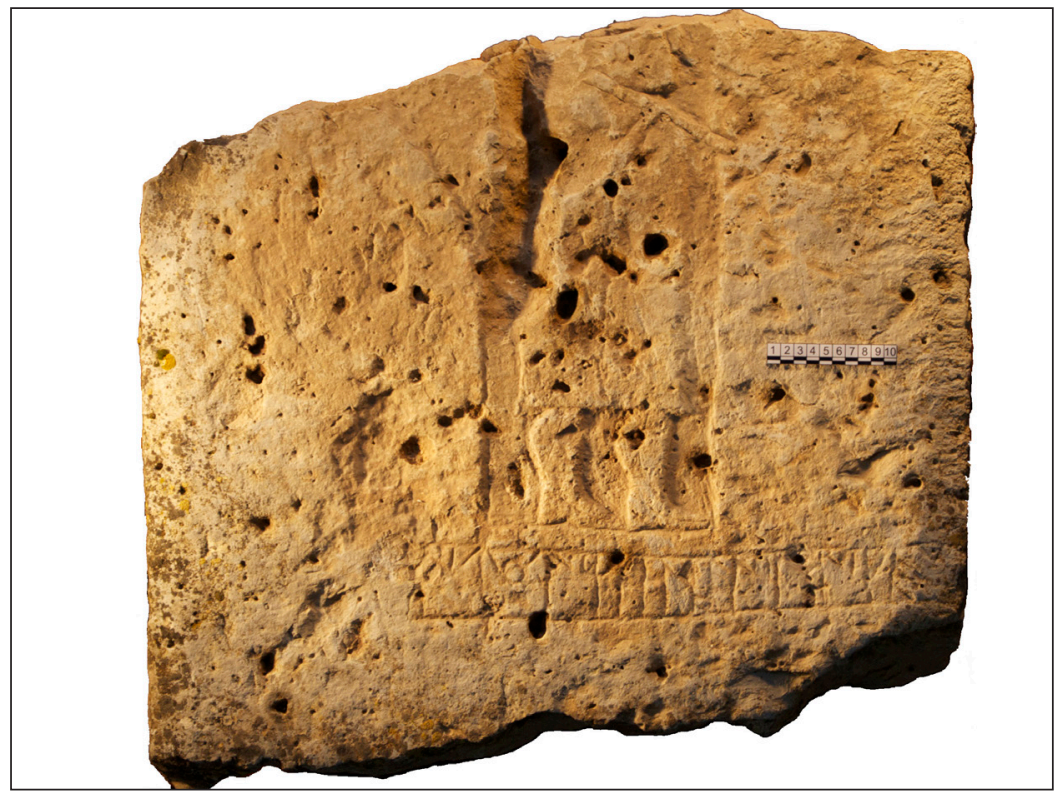

Figura 1. Nueva estela de Clunia (Fotografía J. Gorrochategui).

parece que su desarrollo era vertical, similar a la de Segio Lougesterico (ERClunia: $\mathrm{n}^{\circ} 81$ ) o a ERClunia: anepígrafa C. Difiere tipológicamente de las estelas discoideas, que pueden considerarse el tipo más característico de Clunia en este momento (K.13.1, ERClunia: anepígrafas A y B).

La cara frontal está alisada, pero presenta gran número de orificios característicos del tipo de caliza con el que está elaborada la pieza. Ligeramente escorado a la derecha se ubica un rectángulo rebajado de 17,5 $\mathrm{cm}$ de ancho y que conserva $(39,5) \mathrm{cm}$ de altura. En él se sitúa la figura de un hombre estante realizada en bajorrelieve, casi plano. En su parte inferior se ubica el campo epigráfico, delimitado por dos líneas de $41,5 \mathrm{~cm}$ de longitud y con una altura que oscila entre los 4,5 y $5,5 \mathrm{~cm}$. Formalmente la pieza difiere de las estelas discoideas halladas en Clunia, aunque presenta decoración como aquellas. Sin embargo, la articulación entre imagen y texto es más sofisticada que en K.13.1, en la que el epígrafe tiene el aspecto de un grafito y carece de un espacio propio en lo que parece una composición iconográfica previa. En nuestro monumento cada uno de los dos elementos, escritura e imagen, tiene un espacio propio y perfectamente delimitado.

\section{LA ICONOGRAFÍA}

La imagen se ubica en un campo rectangular y rebajado, que se conserva incompleto en su extremo superior, aunque no parece que sea mucho lo que se ha perdido, pues la figura humana que acoge se preserva casi en su integridad. También está afectada por un surco, de función desconocida (pero probablemente fruto de su reutilización), que se ha practicado en el dorso del personaje.

Se ha realizado en bajorrelieve, prácticamente plano. Esta técnica también se utiliza en otros monumentos clunienses que pueden considerarse coetáneos o inmediatamente posteriores. Son las ya nombradas estelas discoideas, con representaciones de jinetes, y las dos estelas en las que también aparecen caballeros, pero que responden a otro formato, como la de Segio Lougesterico, con cabecera recta (Simón 2017). También puede incluirse en este último tipo un monumento incompleto (ERClunia: $\mathrm{n}^{\mathrm{o}}$ 100; Fig. 6), de cronología temprana, en cuya cara frontal hay rebajado un espacio rectangular en el que aparece un guerrero de pie que porta lanza y escudo circular; el epígrafe se ubica en el margen superior y, aunque redactado en latín, recoge vocabulario institucional celtibérico (Gorrochategui 2013).

En nuestro monumento también aparece una representación similar a la anterior. Es la figura de perfil de un hombre estante que mira a la derecha (Fig. 2). En ambos casos se ha representado una pierna delante de la otra, lo que parece ser un recurso para indicar movimiento. Ambos portan un vestido largo que llega hasta las rodillas y que parece de una única pieza. El brazo derecho de nuestro personaje, desproporcionadamente pequeño, surge del ropaje para 
portar un objeto asido por la mano. No se aprecia ninguna manga ni similar, por lo que hay que pensar en una vestimenta abierta. En otras representaciones iconográficas, como las cerámicas numantinas, son habituales los hombres ataviados con túnica corta (Taracena 1954: 277; Wattenberg 1963: lám. IX, X 6-1241, 12-1247, XI 1-1248, 10-1256, y XIX). Pero quizá en estas piezas clunienses tenemos figurado el conocido sagum, término que parece de origen céltico y que los autores clásicos emplean para denominar los mantos que empleaban pueblos diversos, entre ellos los celtíberos como afirma Diodoro $(\mathrm{V}, 33)$ : форои̃

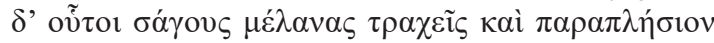

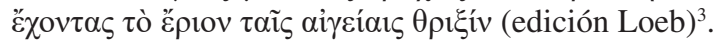
Por su parte, Apiano (Iber. 42) señala sobre los ha-

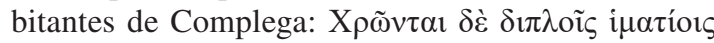

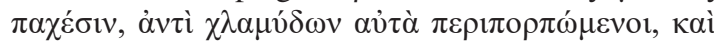

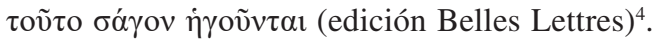

La cabeza está parcialmente perdida. De lo conservado puede deducirse que era una representación esquemática y con un perfil marcado, como sucede en algunas imágenes numantinas (Wattenberg 1963: lám. X 1-1236, 2-1237, 7-1242, 9-1244, XI 5-1252, XVI 1-1295, y XIX). Destacan el prominente mentón y la nariz, mientras que la boca es pequeña; con un círculo ovalado inciso se ha representado la oreja. Con la mano sujeta un astil que se prolonga escasamente en su extremo inferior, aunque lo suficiente como para rebasar la zona rebajada y reservada como campo iconográfico. Está apoyado en el hombro del personaje, pero en este punto la piedra está fracturada e impide reconocer de qué objeto se trata. Lo más probable es que fuese una lanza o un venablo, ya que el espacio disponible hace pensar en un arma de astil corto. También sobre el hombro porta una lanza el jinete de una de las estelas sin inscripción de Clunia (ERClunia: anepígrafa C), mientras que el infante de ERClunia: n $^{\circ} 100$ lleva su lanza empuñada. Sin embargo, el astil de nuestra pieza parece muy corto, con lo que no puede excluirse que fuese otro objeto, quizá un estandarte o un báculo de distinción ${ }^{5}$.

\footnotetext{
3 "Llevan unos bastos mantos negros cuya lana es semejante al pelo de las cabras" (traducción de J. J. Torres, Gredos 2004); sobre el sagum, véase Alfaro 1992: 374-375. Sobre la vestimenta en Celtiberia, véase De Sus Giménez 1988 y Barril 2005 .

4 "Usan un grueso manto doble que abrochan todo alrededor a la manera de las clámides y es lo que consideran un sago" (traducción de F. J. Gómez Espelosín, Alianza 2006). Las fuentes literarias documentan cómo los generales romanos exigían a las ciudades la entrega de estos mantos: Pompeyo pidió 9000 a termantinos y numantinos (Diodoro XXXVI, 16,1) y Lúculo 10000 a Intercatia (Apiano, Iber. 54).

${ }^{5}$ En lo que respecta a los báculos de distinción, también interpretados como signa equitum: Lorrio 2010, con la bibliografía anterior.
}

El hombre está calzado con botas, de las que se han marcado el tacón y el límite de la caña con dos líneas incisas horizontales y paralelas, situadas encima del tobillo. Otra línea incisa recorre el perfil del pie, desde la parte superior del talón hasta la puntera. No parece que represente la suela sino más bien un elemento decorativo como los que aparecen en algunas terracotas podomorfas. El conocimiento sobre el calzado celtibérico es mínimo, pues no se han conservado restos materiales y sólo se documenta a través de la iconografía. Es evidente que algunas figuras humanas representadas en las cerámicas de Numancia llevan calzado, aunque no siempre es un extremo fácil de determinar por el esquematismo que caracteriza a estas imágenes. Ejemplos seguros son los que lucen dos personajes danzantes con cuernos enfundados en sus brazos, pues tienen unos tacones prominentes y punteras elevadas, en los que, además, una línea marca el límite con la pierna (Wattenberg 1963: lám. X, 1-1236; Romero 1976: fig. 4; 1999: 53). Por su parte y, a pesar de su pequeño tamaño, puede comprobarse cómo muchos de los jinetes que aparecen en las monedas celtibéricas calzan botas, de un tipo que se caracteriza por llevar dos tiradores laterales en su extremo superior ${ }^{6}$, que también aparecen en las propias acuñaciones de Clunia (DCPH II: 253, 2. $\left.{ }^{a} 3\right)$. También se representa con botas el guerrero que aparece en otra estela del yacimiento de la que ya hemos hablado (ERClunia: no 100), delimitadas también en ese caso mediante líneas incisas a la altura del tobillo; además — como ya se ha dicho— porta un sayo parecido al de nuestro personaje, aunque lleva un escudo circular y una lanza en ristre (Fig. 6).

Otra fuente de información sobre el calzado la proporcionan los pies de terracota procedentes de ámbito celtibérico (Numancia, Langa de Duero, Arcóbriga y Clunia) y también de la región vaccea (Pintia, Roa y Soto de Medinilla; Wattenberg 1963: 55-56, no 457- 460, Sanz Mínguez 1997: 330-332, y Alfayé 2009: 362-365, figs. 181-189). No siempre es posible determinar si están desnudos o no, pero hay al menos dos ejemplares que con seguridad están calzados, pues los recorren líneas en zig-zag que pudieran representar cordones, las costuras del cuero o bien ser elementos decorativos. El más célebre de ellos es el recuperado en Numancia (Fig. 3; Wattenberg 1963: $n^{\circ}$ 460) y también puede destacarse un ejemplar conservado en el MAN, pero del que se desconoce

\footnotetext{
${ }^{6}$ Gimeno 1951: lám. 2. Este extremo puede comprobarse cuando se cuenta con un buen repertorio gráfico, véase por ejemplo el catálogo de la ceca de Segeda elaborado por Gomis 2001: 38, donde son especialmente evidentes en los denarios de la III emisión (Gomis 2001: 155-157).
} 


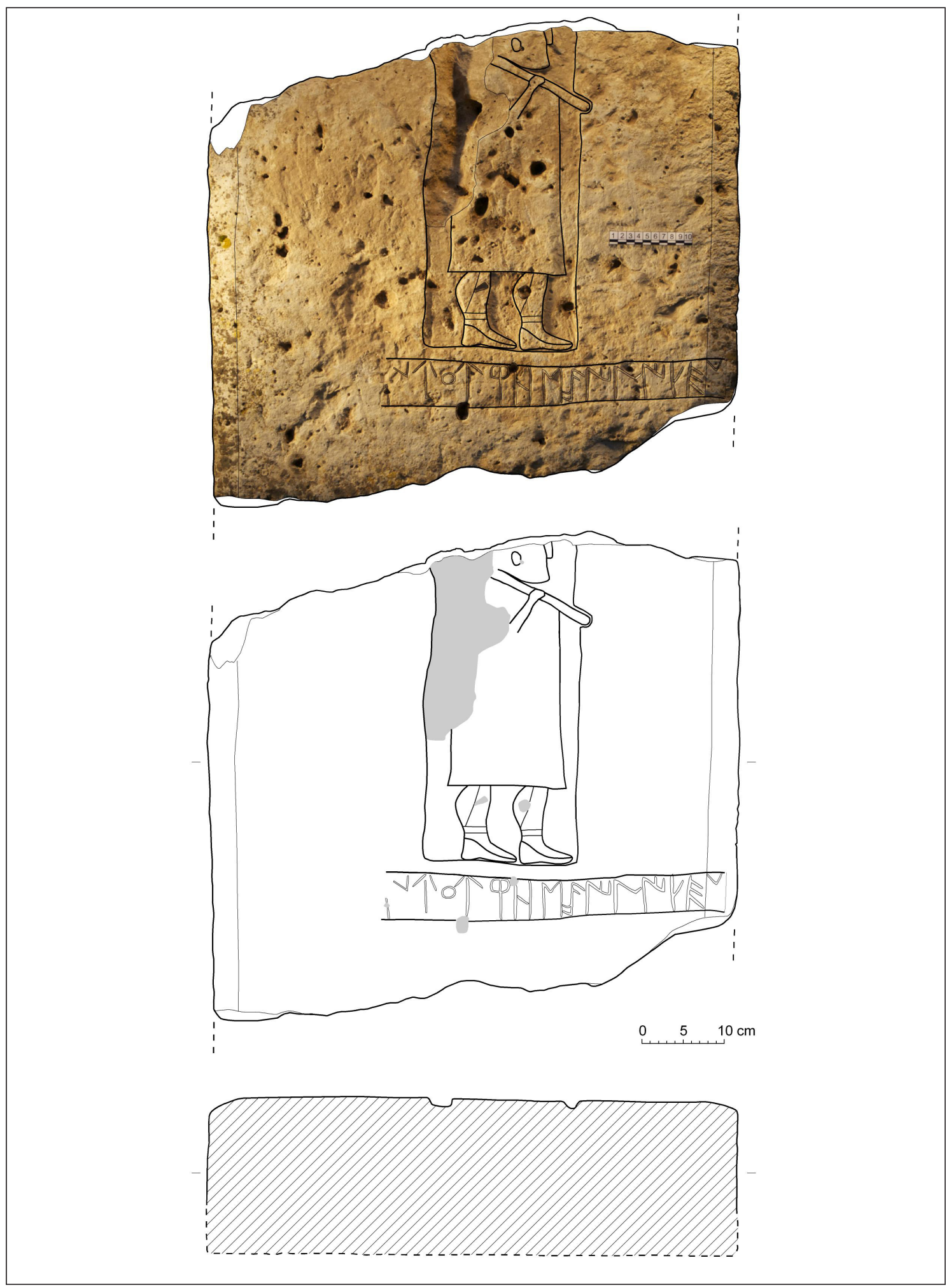

Figura 2. Nueva estela de Clunia (Dibujo de M. C. Sopena). 


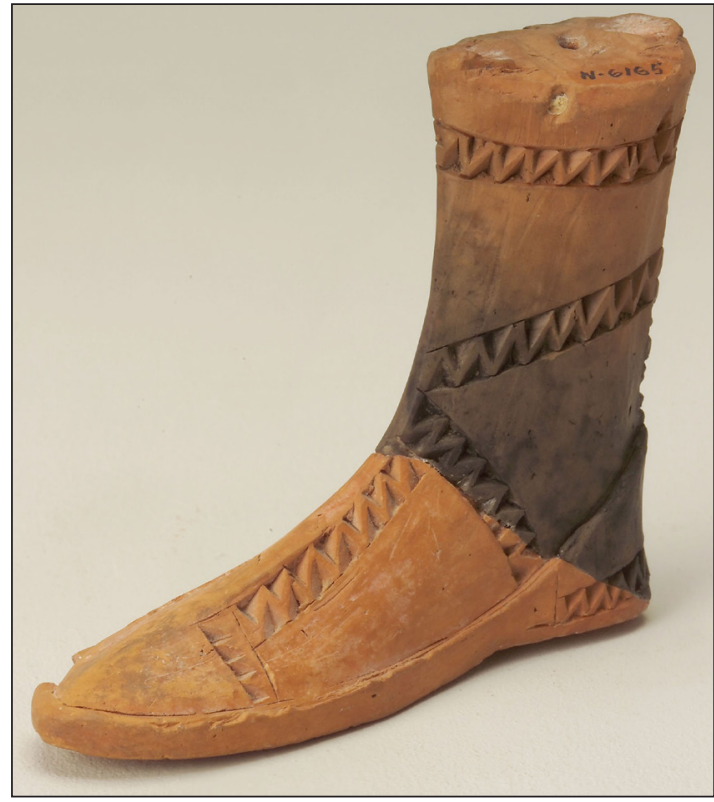

Figura 3. Terracota podomorfa de Numancia (Museo Numantino).

la procedencia. Estos dos últimos destacan por el hecho de que varias líneas zigzagueantes recorren su superficie, asemejándose a la que aparece en las botas de nuestra figura.

Están también nítidamente marcados, además del calzado, los potentes gemelos; hay que subrayar que se trata de un elemento reiterativo en las esquemáticas representaciones humanas del ámbito celtibérico. En ocasiones puede dudarse, por causa precisamente del carácter esquemático de las figuras, si este detalle se debe a que portan grebas, pero parece claro que en la mayor parte de los ejemplos se pretende representar la potencia física? ${ }^{7}$.

Finalmente, hay que destacar que las espinillas están protegidas por sendas grebas (Fig. 4). La representación de las mismas es muy esquemática, pues se reduce a una línea grabada y que nace en la parte posterior del extremo superior de las botas y que en diagonal se prolonga hacia las rodillas. La función de las grebas es proteger las espinillas en los combates cuerpo a cuerpo en los que el enemigo empuña una espada larga o una gran lanza, con las que puede provocar heridas en las piernas y hacer caer a su rival. No son adecuadas para las tropas ligeras sino

\footnotetext{
${ }^{7}$ Wattenberg 1963: lám. X 1-1236, 6-1241, 12-1247, y X $1-1248,10-1256$. Pudieran ser grebas en el personaje que parece estar disfrazado de caballo (Wattenberg 1963: lám. VI 2-1203; Lorrio 1997: 196) y también están muy marcadas en otro individuo que luce igualmente un peculiar atuendo, pero en ambos casos pudieran formar parte de los disfraces.
}

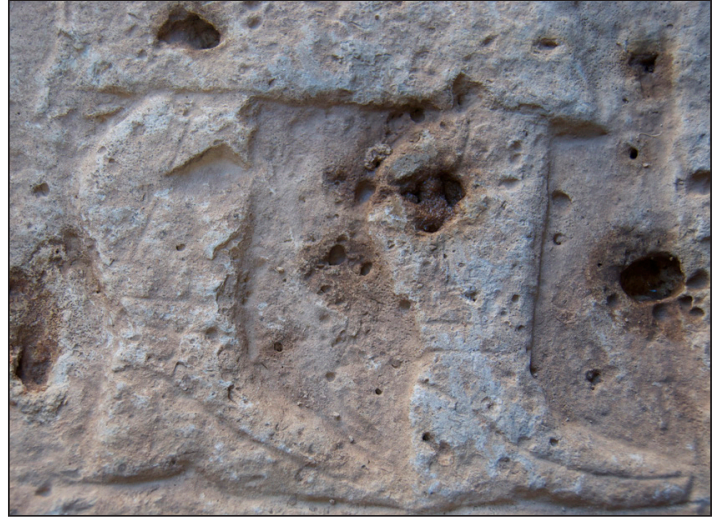

Figura 4. Fotografía de detalle de la estela, en la que puede apreciarse botas y grebas del guerrero (Fotografía J. Gorrochategui).

para la infantería de línea que combate en formación cerrada (Quesada 2004: 99), técnica que utilizaron los celtíberos en batallas campales como se desprende de algunos pasajes de la conquista (Quesada 2006: 162-167). Grebas de metal se documentan en la Península Ibérica desde el Bronce Final y a lo largo de la primera Edad del Hierro y también en la iconografía de dicho periodo, como la escultura de Elche y el Cerrillo Blanco de Porcuna. Sin embargo, desaparecen a partir del siglo IV a. E. (Farnié y Quesada 2005).

No obstante, las fuentes literarias nos informan del uso de grebas en fechas posteriores. Así lo hace Estrabón $(3,3,6)$ sobre lo lusitanos y Diodoro $(\mathrm{V}, 33)$

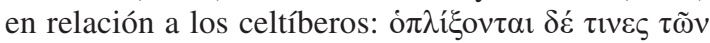

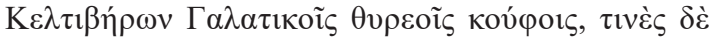

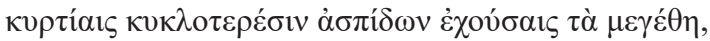

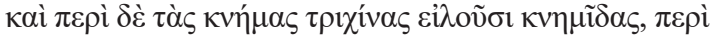

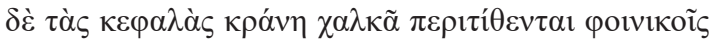

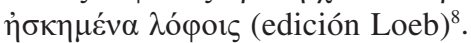

Diodoro especifica que se trata de piezas realizadas con material orgánico, por lo que no se han conservado resto alguno de ellas. Sí las tenemos documentadas gracias a la iconografía numantina. En algunas cerámicas no puede determinarse con certeza, de nuevo por su esquematismo, si los personajes representados portan o no grebas ${ }^{9}$. Aunque hay un ejemplo incontrovertido que ofrece el conocido como "vaso de los guerreros" (Fig. 5; Wattenberg 1963: no 1166, lám. XVI 1-1295; Romero 1976: no 20, fig.

\footnotetext{
8 "En cuanto a las armas, algunos celtíberos van pertrechados con escudos ligeros como los de los galos, y otros con unos escudos convexos redondos que tienen el tamaño de una aspís; en torno a las piernas envuelven grebas de pelo, y en sus cabezas se ponen yelmos de bronce adornados con penachos purpúreos" (traducción de J. J. Torres, Gredos 2001).

Grebas con pelos parece portar el guerrero de Mosqueruela (Lorrio y Royo 2013: 88).
} 
4, 1999). Es una de las más conocidas cerámicas numantinas, célebre por su excepcional iconografía. En ella aparecen dos guerreros afrontados, de cuya panoplia destacan los yelmos con cimeras zoomorfas, los escudos circulares, la piel que parece recubrir a uno de los combatientes, las lanzas y la espada. Pero también las grebas, que se representan con notable detalle: colocadas entre las rodillas y las botas, se ajustan mediante cordeles a la pantorrilla y el tobillo y cubren la parte anterior de la pierna (las espinillas), mientras que los gemelos quedan libres ${ }^{10}$. Las portan ambos guerreros y es posible que también las llevase un tercer personaje representado en otro fragmento de este vaso que actualmente está perdido ${ }^{11}$.

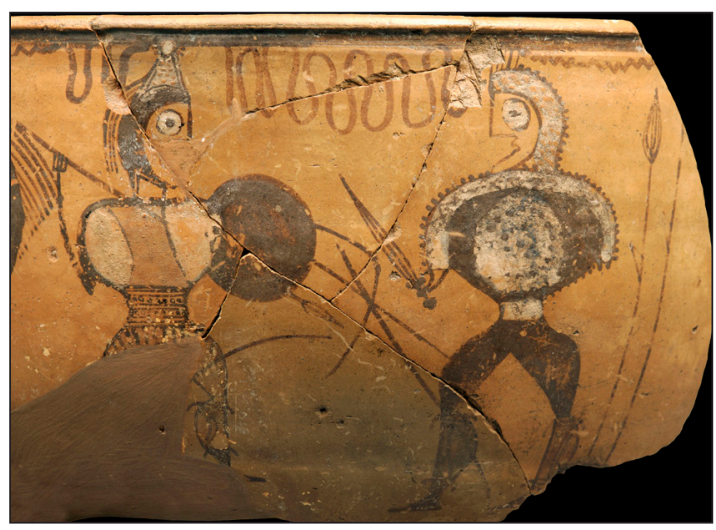

Figura 5. Vaso de los guerreros de Numancia (Museo Numantino).

Las piernas del peón de la ya varias veces citada estela de Licirico (ERClunia, $\mathrm{n}^{\circ}$ 100) están recorridas por sendas líneas dobles rayadas. Su disposición no es idéntica a las grebas de nuestro ejemplar, pero probablemente están representando el mismo objeto, ya que se disponen en paralelo a las espinillas, para curvarse en su extremo (Fig. 6).

El detalle de las grebas es muy significativo, pues permite caracterizar al personaje de nuestro monumento como un guerrero, ya que, como hemos visto, no es completamente seguro que porte una lanza sobre su hombro. Dicho extremo tiene su relevancia, pues en

${ }^{10}$ Hay variaciones significativas sobre estos detalles en los diferentes dibujos que se han publicado de este vaso: Excavaciones en Numancia: lám. XLVIII (dibujo de D. M. A. Álvarez); Taracena 1954: fig. 174; Wattenberg 1963: lám. XVI 1-1295; y Romero 1976: fig. 4.

${ }^{11}$ Documentado por un dibujo de D. M. A. Álvarez, Excavaciones en Numancia: lám. XLVIII. Quizá también se pudieran estar representando unas grebas en un fragmento de cerámica polícroma en el que solo se conservan las piernas de un individuo (Wattenberg 1963: lám. XI 6-7-1253; Romero 1976: fig. $\left.8, n^{\circ} 19\right)$.
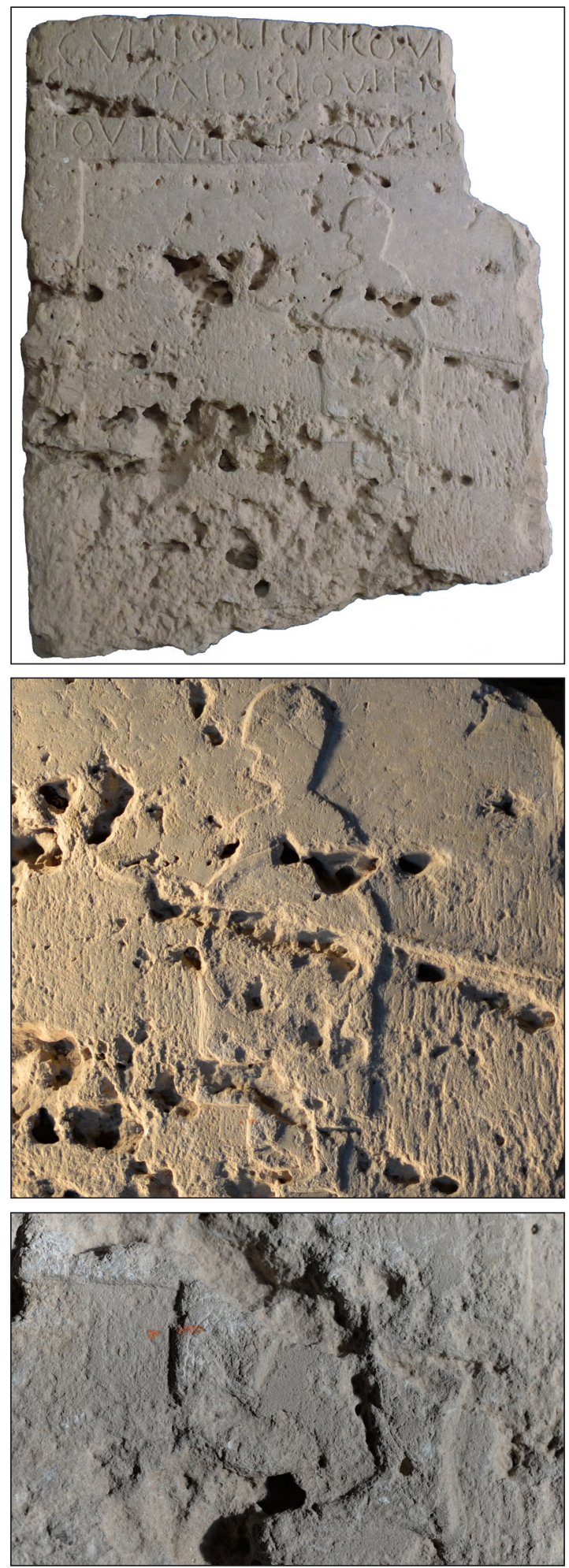

Figura 6. Fotografía general y de detalle de la estela de Licirico (Fotografías J. Gorrochategui). 
todos los monumentos coetáneos de la ciudad siempre se representan soldados, vayan a caballo o sean, como en este caso, infantes.

\section{LA INSCRIPCIÓN}

\subsection{LECTURA Y TRANSCRIPCIÓN}

Se ubica bajo la representación del personaje descrito. Se desarrolla en una única línea de escritura constreñida por dos líneas de guía, cuya longitud alcanza los 41,5 cm y delimitan una caja de escritura con una altura que oscila entre 4,5 y $5,5 \mathrm{~cm}$ (Fig. 7).

El campo epigráfico queda así delimitado por líneas incisas, pues las guías se han grabado como el resto del epígrafe, algo infrecuente en la epigrafía latina pero relativamente común en las inscripciones paleohispánicas sobre piedra. En el corpus ibérico se conoce un número significativo de textos en los que se han grabado las líneas de guía, especialmente comunes en las inscripciones que proceden del área del Maestrazgo. Pero, cartelas propiamente dichas, solo se documentan en dos inscripciones: $M L H$ III-1, E.9.1 y F.3.1 (= BDH: CS.05.01 y CS.08.01 respectivamente) $)^{12}$.

En lo que respecta a la Celtiberia, la única inscripción en la que se han grabado las líneas de guía es el excéntrico ejemplar recuperado en Ibiza (K.16.1 $=B D H$ : IB.01.01), detalle por el que se ha supuesto la influencia de la práctica epigráfica ibérica en este texto (en último término, Velaza 2015). Ahora bien, en dos textos celtibéricos editados recientemente sí aparecen líneas de guía: el primero es el procedente de El Pueyo (Belchite, Zaragoza), en el que la caja de escritura aparece delimitada por arriba y abajo (Rodríguez y Diez de Pinos $2014=$ = BDH: Z.17.01); y el segundo es un epígrafe de la propia Clunia, en el que hay una línea grabada sobre el texto, que parece haberse empleado por el lapicida como referencia (Gorrochategui $2014=$ BDH: BU.06.04).

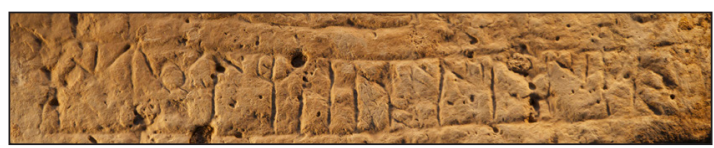

Figura 7. Detalle de la inscripción (Fotografía J. Gorrochategui).

${ }^{12}$ Según el dibujo que de esta última ofrece A. Valcárcel. Un ejemplo singular lo proporciona la pieza del Bell Lloc (BDH: CS.10.01), pues en ella aparecen dos cartelas (Arasa 1989). BDH son las iniciales del Banco de Datos Hesperia: http://hesperia.ucm.es/.
El texto no ofrece grandes dificultades de lectura, solo el desgaste de su flanco derecho en la zona biselada plantea dudas sobre la existencia de un último signo. A primera vista parece que el texto termina en el decimotercer signo, es decir en - $e$, aunque las líneas incisas limitadoras del campo continúan claramente en la zona biselada. El texto no está centrado ni en la superficie de la estela ni respecto a la figura, de modo que es factible que el lapicida no pudiera incluir todo el texto en la parte frontal de la estela y se viera forzado a continuar en la zona biselada. Luego haría las líneas o la cartela incluyendo en su interior todo el texto. En la parte derecha correspondiente al final del texto se aprecia un trazo vertical, que no sabemos si es el cierre de la cartela, el asta vertical del decimocuarto signo o ambas cosas a la vez. La existencia o no de una cartela tampoco puede determinarse en el otro extremo del epígrafe, pues se ha perdido parte de la superficie pétrea y solo se aprecia el extremo inferior del asta vertical de la primera $m$.

Los grafemas legibles que componen el texto ocupan la totalidad del campo epigráfico. La paleografía de los signos, según la clasificación de $M L H$ IV, p. 443, es: n1, u1, ku3, u1, r5, o3, s1, ki2, i, n1, i, ḿ=n2 y e3. Su módulo es: 5,2, 5,2, 2,2, 4,7, 5, 4,2, 4,1, 4,1, 4,2, 4, 4, 4,2 y $4 \mathrm{~cm}$, respectivamente; destaca el pequeño tamaño de $k u$ frente al resto de grafemas, idéntico al que se emplea en la inscripción cluniense BDH: BU.06.04 editada por Gorrochategui (2014).

La lectura de la inscripción, en escritura continua sin interpunciones, es: mukuuroskiimine+. El primer problema de lectura corresponde al décimo signo, que hemos transcrito por $m$. Otra posibilidad es leer $l$. La diferencia entre ambos signos estriba en que la $m$ posee un pequeño trazo vertical al final del asta oblicua, que la $l$ no tiene. El primer signo del texto, aunque parcialmente roto, muestra una correcta ejecución de $m$. En el décimo signo no se aprecia esta asta vertical, lo que en principio inclinaría a identificar el signo como $l$, pero nos parece que existe un trazo oblicuo en la piedra, no casual sino intencionado, cuya dirección anormal se debe sin duda a que el lapicida tuvo que inclinar este último trazo para evitar una coquera situada justo encima, en la trayectoria vertical del trazo. El segundo problema concierne a la identificación del último signo grabado sobre el bisel. Se vislumbran sin demasiada dificultad el asta vertical derecha y a su izquierda dos trazos en forma de ángulo en la parte superior de la caja, lo cual permitiría identificar una $\mathrm{s} 1 .{ }^{13} \mathrm{Su}$ asta izquierda estaría

${ }^{13}$ Existen otras posibilidades teóricas de interpretar estos trazos, pero de mucha menor plausibilidad; el trazo vertical final podría ser el silabograma $b a$, y si el asta final y el ángulo 
justo sobre la arista del bisel, a muy poca distancia o casi rozando los extremos de los trazos oblicuos de la $e$; aunque la mayoría de los signos mantienen espacios entre sí, hay casos en que los trazos horizontales de unos tocan las astas verticales de otros, como ocurre con los signos séptimo y octavo ( $s k i)$ y décimo y undécimo $(m i)$.

Se trata de un texto que utiliza la variante occidental del signario celtibérico, pues en el epígrafe se emplean los dos signos para las nasales que lo caracterizan. Es la variante que se usa en las leyendas monetales de la ceca local ( $M L H$ I: A.67) y en las otras inscripciones en piedra en las que este extremo puede determinarse (K.13.1, K.13.2 у BDH: BU.06.04). Parece, por tanto, variante propia de la ciudad, algo que casa bien con su ubicación geográfica. Es igualmente destacable que utilice la redundancia vocálica de forma sistemática: a los dos silabogramas que aparecen en el texto ( $k u$ y $k i)$ les sigue el signo de la correspondiente vocal ( $u$ e $i$, respectivamente). Esta peculiaridad se documenta en un pequeño grupo de textos celtibéricos y con los nuevos hallazgos también parece ser característica de Clunia, pues se utiliza en las ya mencionadas K.13.1, K.13.2 (= BDH: BU.06.01 y .02) у BDH: BU.06.04. ${ }^{14}$

Finalmente, en lo que toca a sus dos silabogramas el epígrafe presenta variantes simples $(k u$, sin punto interno) y complejas ( $k i$, doble apéndice en sus dos extremos), compatibles con el sistema dual de expresión de la sonoridad (Jordán 2005; 2007), aunque debido a la brevedad del epígrafe no se documenta explícitamente la oposición de las dos variantes. De todos modos es llamativo que las variantes usadas sean las que estadísticamente menos se emplean en cada caso. Según la lista de variantes paleográficas ( $M L H$ IV: 445) $k u$ con punto interno (ku1, ${ }^{15} \mathrm{ku} 2$ y ku4) es cinco veces más frecuente que la variante sin punto ku3, del mismo modo que la variante compleja ki2 solo se documenta en otras dos inscripciones: K.14.1 (= BDH:

anterior formaran parte de un único signo, podría pensarse también en una $m$ levógira. Ahora bien, aparte de las dificultades paleográficas mismas (en caso de $b a$, que entre $e$ y $b a$ habría demasiado espacio y que sería el único silabograma no redundante, o, en caso de $m$, la rareza de cambiar de dirección de escritura además de utilizar el signo con trazo oblicuo y no vertical como en el signo 1 ), tendríamos finales en -eba o en -em infrecuentes en celtibérico (MLH IV: 467, 471).

${ }^{14} \mathrm{El}$ estado de K.13.3 (BDH: BU.06.03) es muy fragmentario como para poder determinar este extremo. Fuera de Clunia la redundancia se documenta en Numancia (K.9.2 y quizá K.9.5 = BDH: SO.01.02 y .05), una de las téseras de Sasamón (K.14.1 = BDH: BU.01.01) y la tésera de Belorado (K.24.1 = $B D H$ : BU.03.01).

${ }^{15}$ En la tabla de signos de la pág. 443 ku1 está dibujado, por error, sin punto interno, pero la relación de inscripciones que lo contienen (p. 445) está bien.
BU.01.01, Sasamón) y K.23.2 (= BDH: SO.06.02, Uxama), ambas en signario occidental y la primera además redundante (Jordán 2005; 2010). Hay que mencionar que uno de los pocos casos de empleo de la variante ku3, según la lista de Untermann citada, es la inscripción K.13.2 (= BDH: BU.06.02), procedente de Clunia, con la expresión de una secuencia referida a nombre de persona (mukuukaaiu), cuyo inicio recuerda al comienzo de nuestra inscripción. Clunia ha ofrecido también recientemente otro caso de ku3 (= BDH: BU.06.04), donde la grafía kuustuunuo hace referencia al nombre de persona transmitido como Gustunus en epigrafía latina de la zona.

Teniendo en cuenta, por tanto, el empleo de las variantes duales, la transcripción del texto sería: muguroskimine $(s)$.

\subsection{Segmentación Del teXto E INTERPRETACión}

Como ya hemos señalado, el epígrafe está redactado en escritura continua, sin separador alguno de palabras, aunque lo más plausible es que haya que establecer en el texto, al menos, una cesura. Pero hay más de un lugar donde puede hacerse un corte de palabras, dando lugar a lecturas e interpretaciones diferentes de la inscripción. A esto se añaden, además, las variantes de lectura arriba indicadas, correspondientes al décimo signo y al final del texto.

a. Si partimos del paralelo onomástico de K.13.2 (BDH: BU.06.02), donde podemos aislar un nombre de persona mukuu (nom. sing. de tema en $-n$ ), nos quedaría un resto roskiimine(s?) o roskiiline(s?). Una forma que terminara en - $e$ no tendría mucha justificación en la sintaxis nominal esperable en un epitafio y nos sugeriría más bien una forma verbal, en concreto una $3^{\mathrm{a}}$ pers. sing. de perfecto ${ }^{16}$. Yendo por ese camino, no es descabellado pensar que ro(*pro-) es el preverbio atestiguado en otros verbos celtibéricos, como robiseti (Bronce de Botorrita I, K.1.1 = BDH: Z.09.01), y de amplio uso en irlandés antiguo, precisamente alineado con formas de perfecto o valores perfectivos. El resto sería el tema verbal, o quizá podría verse en la - $s$ - el resultado del anafórico en posición infijada entre preverbio y tema verbal, que en este caso debería referirse al sujeto, es decir a mukuu (= Mucco / Muggo?), y no a ningún objeto como ocurre en la expresión to-so-kote de la inscripción gala de Vercelli. Lo que nos queda, kiiline

\footnotetext{
${ }^{16}$ En el ámbito del verbo una final -es podría ser interpretada teóricamente como desinencia de $3^{\mathrm{a}}$ sing. de aoristo sigmático, como en tures (*dū-reg-s-t, Prósper 2013-2014: 145), pero no alcanzamos a saber cuál sería la raíz del verbo.
} 
= kline, mejor que kiimine, tendría muy buen paralelo en el verbo griego $\kappa \lambda i v \omega$ 'inclinarse, acostarse', latino clinare 'inclinar' y germánico (sajón ant. hlinon, alto alem. ant. hlinen 'inclinarse'). La - $n$ - de la forma verbal remonta a una antigua formación de presente con $-n$ - infijada, que no existía originariamente en las formas de perfecto (como se aprecia en griego $\kappa \varepsilon ́ \kappa \lambda \imath \mu \alpha l$ ), pero el germánico y el latín muestran que dicha - $n$ - se extendió a todo el verbo, con lo que una similar expansión analógica puede concebirse también para el celtibérico. Deberíamos también admitir que el verbo evolucionó semánticamente del sentido de 'inclinarse' a 'acostarse o estar acostado o tumbado' como ocurrió en griego (donde tenemos formaciones nominales derivadas del tema de presente como

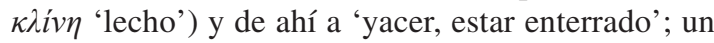
cambio semántico paralelo ocurrió en falisco cupat, atestiguado sobre varias tégulas sepulcrales, mismo verbo que latín cubare 'estar acostado' (Giacomelli 1963: 94, 240-241). El preverbio ro- ayudaría al sentido: 'inclinarse completamente, hasta el final'. Así la inscripción diría: "Mucco, él (está) enterrado". Esta interpretación, para la que, como hemos visto, se pueden aducir paralelos comparativos lingüísticos en otras lenguas indoeuropeas, presentaría un texto sin paralelos textuales en celtibérico ${ }^{17} \mathrm{y}$, lo que es más inquietante — sollicitor cogitans-, haría del celtibérico un proto-gaélico en ciernes, con formas pronominales infijadas, aunque sin la reduplicación ni el ablaut canónicos del irlandés. Pero existen otras segmentaciones, que se sustentan en paralelos cercanos y que evidentemente no están tan cargadas de consecuencias lingüísticas.

b. La interpretación más plausible, teniendo en cuenta la lectura adoptada para el décimo signo y la existencia de restos de un decimocuarto signo $(s)$, es aislar como nombre de persona la secuencia mukuuros (nom. sing.) o mukuuro (gen. sing.). El nombre cuenta con un paralelo exacto trasmitido en un epígrafe latino procedente de Alcubilla de Avellaneda (Soria) ${ }^{18}$, en el que se documenta Mugurus por dos veces, una en dativo Muguro como cognomen del finado benefi-

${ }^{17}$ Esta no es una objeción grave, ya que ni en las inscripciones de Clunia ni en el escaso conjunto de epígrafes pétreos celtibéricos se puede sistematizar formulario alguno. Únicamente se recogen fórmulas onomásticas más o menos complejas: retukeno (K.12.1), mata abiliko man ke(ntis) (K.8.1) y tirtanos abulokum letontunos k(entis) belikios (K.16.1), que en algunos casos aparecen seguidas de elementos adicionales, como quizá la denominación de un segundo individuo (K.8.1), términos de difícil lectura y clasificación (K.12.1) o un apelativo del léxico común como monimam (K.26.1).

${ }_{18}$ Morales y Jimeno 1982: 159-160, lám I.; Borobio et alii 1987, cuya lectura es: [D. M.] / [L Pompeio L f] Muguro. L. [Pompeio] / [L.f. ...]. Pompeia. L.f. [Mariana] / [Ma]ria. L.f. Muguri. $u[$ xor $] /[\ldots]$. ciario de la inscripción y otra en genitivo Muguri en la denominación onomástica de su esposa comitente de la inscripción: en ambos casos es clara la grafía con $\mathrm{G}$ del nombre, lo cual coincide con la variante sencilla ku3 de nuestra inscripción, que estaría indicando consecuentemente el carácter sonoro de la consonante. El resto kiimines o skiimines sería un segundo nombre de persona que en principio haría referencia al padre del difunto. Esta interpretación, aunque esperada como texto de un epitafio, presenta sin embargo una denominación personal no canónica en celtibérico, al faltarle la indicación de la agrupación familiar. Por otro lado, los finales en -es no son frecuentes en las terminaciones de los nombres de persona atestiguados en celtibérico, habiendo dudas en algunos casos de si se trata de nombres de persona o de población o incluso de formas verbales. El paralelo más seguro, con diferencia, de un gen. sing. terminado en -es es steniotes de la pátera de Gruissan (K.17.1 = $B D H$ : AUD.04.01); quizá lo sean también itelauses y buntunes de una tésera de Viana $(\mathrm{K} .18 .3=B D H$ : NA.01.03) o aletuures de otra de Sasamón (K.14.1 = $B D H$ : BU.01.01), pero en estos dos casos, al no estar inmersos en una secuencia onomástica, no está asegurada su función de gen. sing. de nombre personal, pudiendo recibir otras interpretaciones; tures, repetido en varios textos largos (K.0.7 = BDH: SP.02.03 y $B D H$ : TE.03,01), se explica relativamente bien como verbo. A pesar de las pequeñas inseguridades en la lectura y de la poco usual fórmula onomástica empleada en la inscripción, nos parece que la interpretación más plausible sea la indicación del nombre del difunto, probablemente en genitivo, como en el cipo de retukeno de Langa de Duero (K.12.1 = BDH: SO.04.01), seguido del nombre del padre: Muguro Skimines "(tumba) de Muguros (hijo) de Skiminis".

Como hemos dicho, Muguros está documentado en epigrafía latina y forma parte de un conjunto de nombres con representación en Celtiberia, empezando por la propia Clunia donde se atestiguan mukuи con ku3 [gu] en K.13.2 y Muggio como nombre de mujer (Valeria Muggio, HEp 1, 151; HEp 13, 199; ERClunia: $\mathrm{n}^{\circ}$ 81). Una formación temática en gen. sing. sobre la misma raíz la hallamos muy probablemente en muko de Numancia (K.9.1 = BDH: SO.01.01, Simón 2007). En cambio, Skiminis carece de paralelos por el momento, al igual que un hipotético Skriminis.

\section{UNA NOTA DE LECTURA SOBRE K.13.1 = BDH: BU.06.01}

Las inscripciones celtibéricas sobre piedra, si excluimos los esgrafiados rupestres (K.3), son muy 
escasas. Presumiblemente son epitafios, aunque todas ellas carecen de contexto arqueológico o han aparecido reutilizadas. No obstante, la presencia de estelas también apunta a dicha función, aunque buena parte de las piezas se conserva incompleta y su clasificación tipológica es, por tanto, incierta (Simón 2013: 88-90, Gorrochategui 2017). La mayoría son hallazgos aislados: El Pedregal (Guadalajara, K.1.1 y K.1.2), Torrellas (Zaragoza, K.8.1), Belchite (Zaragoza, Rodríguez y Diez de Pinos 2014), Trébago (Soria, K.10.1), Langa de Duero (Soria, K.12.1), Osma (Soria, K.23.1), Retortillo (Cantabria, K.26.1) y el excéntrico ejemplar procedente de Ibiza (K.16.1). Clunia sobresale dentro de este panorama, con cinco ejemplares, pues en $M L H$ IV se recogen tres inscripciones pétreas procedentes de esta ciudad: K.13.1, K.13.2 y K.13.3, a las que se suman la editada por Gorrochategui (2014) y la que se da a conocer en este artículo.

Durante el estudio de la nueva inscripción hemos podido revisar la tercera de las recogidas en $M L H$ IV (K.13.3), que no es más que un pequeño fragmento y que fue editada por P. Palol y J. Vilella en su catálogo de la epigrafía de Clunia (ERClunia: $\mathrm{n}^{\mathrm{o}} 3$ ) y que también se conserva en los almacenes del Museo de Clunia. J. Untermann no llegó a realizar autopsia y lo cierto es que pueden corregirse las lecturas dadas, tras haber realizado una inspección directa de la pieza. Efectivamente, se trata de un pequeño fragmento alargado muy estrecho, pero conserva lo suficiente para poder relacionarlo con otros monumentos de la ciudad (Fig. 8). En primer lugar, pueden diferenciarse dos zonas: un borde superior en el que aparece el epígrafe y un espacio debajo rebajado que parece actuar como campo iconográfico, pues en él se conserva lo que pudiera ser parte de una lanza, disposición de texto e imagen que comparte con la estela de Licirico (ERClunia $\mathrm{n}^{\circ} 100$; fig. 6). También es posible reconocer un pequeño vestigio del relieve en la parte inferior, que pudiera ser el pie de un infante, que portaría su arma sobre el hombro. La figura del guerrero tendría, por tanto, una altura aproximada de $40 \mathrm{~cm}$, similar a la del peón que aparece en la estela de Licirico, de $33,5 \mathrm{~cm}$, y a la del guerrero de la pieza que editamos aquí, que alcanza los $38,5 \mathrm{~cm}$.

El campo epigráfico estaba flanqueado por el margen superior de la estela y el comienzo del rebaje del campo iconográfico, que proporcionaban las referencias superiores e inferiores a modo de guía de escritura. Del texto apenas se conservan dos signos legibles de 4,5 cm de altura, de buena factura, y restos de otros dos signos en la parte inicial y final del campo conservado: [---]+ro : +[---], frente a las lecturas de ERClunia no 3: [--- Agi? ro[ca?---], y $M L H$ IV: ++ro+. Se documenta un final en -ro que pudiera ser un genitivo. Del primer signo ilegible se percibe un asta vertical, que por la distancia que deja a su derecha hasta la $r$ bien pudiera corresponder a una $i$ (de la que se ha perdido la parte superior del signo por rotura de la piedra). Del último signo también queda solamente un trazo vertical, incompatible con la lectura $k a$ de Palol y Vilella, pero compatible con más de un signo, como $b a, s, m, e$, etc.

Es interesante señalar el empleo de interpunción, un separador compuesto por tres puntos superpuestos, ya que en las otras inscripciones celtibéricas de Clunia se hace uso de la scriptio continua.
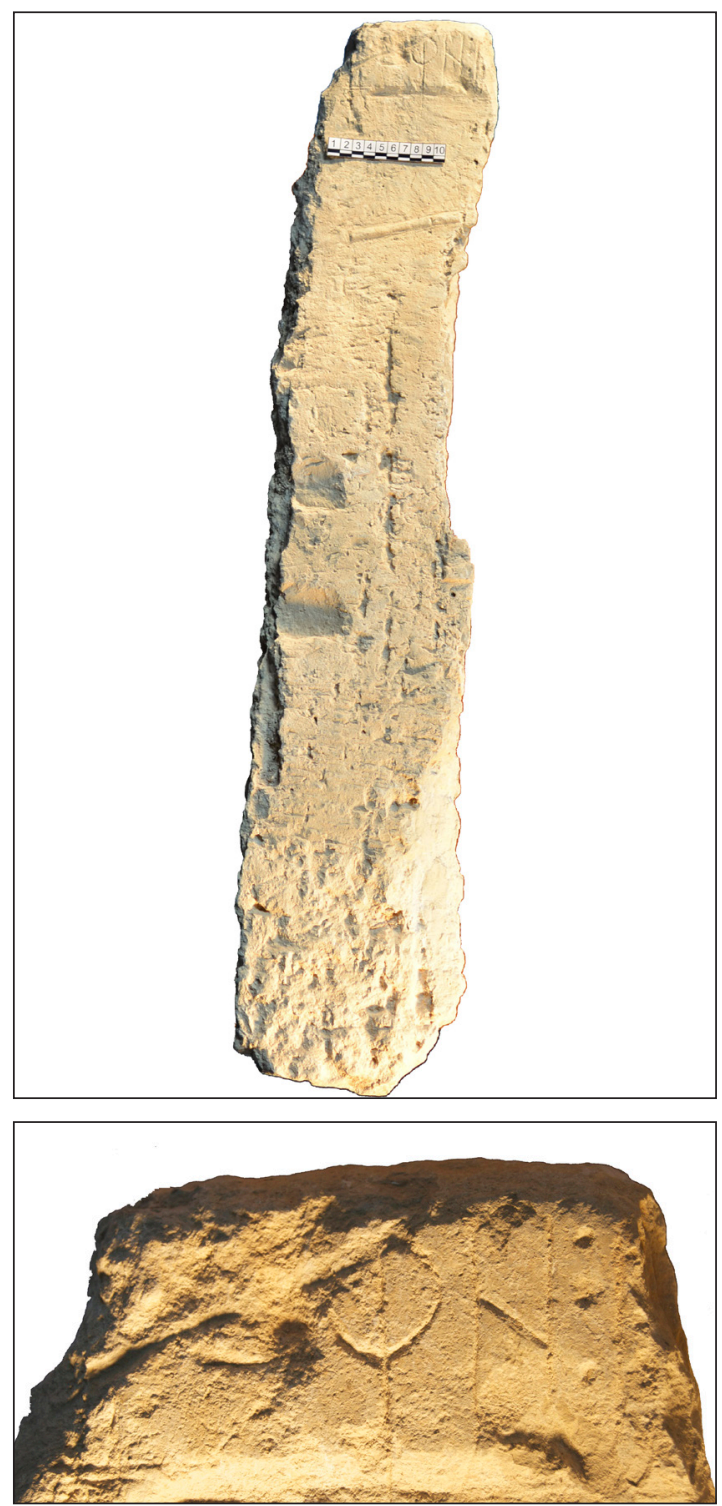

Figura 8. Inscripción celtibérica MLH IV: K.13.3 (Fotografías J. Gorrochategui). 


\section{CRONOLOGÍA}

El conjunto de la epigrafía celtibérica se data en los siglos II y I a. n. e., aunque algún texto puede ser ligeramente posterior. Sin embargo, apenas hay criterios para precisar más la datación de las inscripciones, especialmente cuando carecemos, como en este caso, de contexto arqueológico. Las otras inscripciones clunienses también carecen de él, pero se han datado con anterioridad a la Era en función de dos criterios: la presencia de caetrae (K.13.1) y por el propio hecho de tener textos paleohispánicos (García y Bellido 1949: 324-327). Efectivamente, la datación de estos epígrafes en el siglo I a. n. e. parece adecuada, centuria en la que la ciudad también acuña moneda con leyendas celtibéricas ( $M L H$ I: A.67). Pero en este caso también contamos con un elemento de juicio adicional y es que varias de estas piezas (ERClunia: $\mathrm{n}^{\circ}$ 3, 100 y anepígrafa C; Abásolo 2008: 229; Simón 2013: 90; Gorrochategui 2014: 230) fueron reutilizadas en la construcción de la ciudad imperial y de su foro, cuya obra se inició durante el reinado de Tiberio, lo que nos ofrece una fecha ante quem para las inscripciones celtibéricas de Clunia (Simón e. p.).

\section{FUENTES}

$\mathrm{BDH}=$ Banco de Datos Hesperia. Banco de datos on line de lenguas paleohispánicas. http://hesperia. ucm.es/index.php.

DCPH $=$ García-Bellido, M. P. y Blázquez, C. 2001: Diccionario de cecas y pueblos hispánicos, Madrid.

ERClunia = Palol, P. y Vilella, J. 1987: Clunia II. La epigrafía de Clunia, Madrid.

Excavaciones en Numancia = Excavaciones en $\mathrm{Nu}$ mancia. Memoria presentada al Ministerio de Instrucción Pública y Bellas Artes por la Comisión Ejecutiva, Madrid, 1912.

MLH = Untermann, J. 1975-1997: Monumenta Linguarum Hispanicarum, Wiesbaden.

\section{BIBLIOGRAFÍA}

Abásolo, J. A. 2008: "El primer horizonte de escultura celtíbero-romana en la Meseta: las estelas de guerreros", Escultura romana en Hispania V, Murcia, 223-233.

Alfaro, C. 1992: "Sagum Hispanum. Morfología de una prenda ibérica", Homenaje a Enrique Plá, Valencia, 373-379.

Alfayé, S. 2009: Santuarios y rituales en la Hispania céltica, Oxford.
Arasa, F. 1989: "Una estela ibérica de Bell-Lloc (La Plana Alta)", Archivo de Prehistoria Levantina 19, 91-99.

Barril, M. 2005: "Adorno y vestimenta", Celtíberos. Tras la estela de Numancia, Soria, 367-374.

Borobio, M. J., Gómez-Pantoja, J. y Morales, F. 1987: "Diez años (y dos siglos) de epigrafía soriana", Celtiberia 74, 239-258.

De Sus Giménez, M. L. 1988: "La Indumentaria", Celtíberos, Zaragoza, 99-105.

Farnié, C. y Quesada. F. 2005: Espadas de hierro, grebas de bronce. Símbolos de poder e instrumento de guerra a comienzos de la Edad del Hierro en la Península Ibérica, Murcia.

García y Bellido, A. 1949: Esculturas romanas de España y Portugal, Madrid.

Giacomelli, G. 1963: La lingua falisca, Firenze.

Gimeno Rúa, F. 1951: "La indumentaria del jinete ibérico", Crónica-catálogo de la I exposición nacional de numismática, Tarrasa, 53-63.

Gomis, M. 2001: Las acuñaciones de la ciudad celtibérica de Segeda-sekaiza, Zaragoza.

Gorrochategui, J. 2013: "TOTIVS TREBAQVE: instituciones políticas peregrinas arévacas", E. Ortiz de Urbina (ed.), Magistrados locales de Hispania. Aspectos históricos, jurídicos, lingüísticos, Vitoria, 159-169.

Gorrochategui, J. 2014: "Nueva inscripción funeraria celtibérica procedente de Clunia", Palaeohispanica 14, 229-236.

Gorrochategui, J. 2017: "Soporte, imagen y escritura en las inscripciones funerarias celtibéricas", $\mathrm{Pa}$ laeohispanica 17, 291-314.

Jordán, C. 2005: “¿Sistema dual de escritura en celtibérico?", Palaeohispanica 5, 1013-1030.

Jordán, C. 2007: "Estudios sobre el sistema dual de escritura en epigrafía no monetal celtibérica", Palaeohispanica 7, 1101-142.

Jordán, C. 2010: "[K.14.1]: una nota de epigrafía paleohispánica", Zeitschrift für Papyrologie und Epigraphik 172, 155-158.

Lorrio, A. J. 1997: Los celtíberos, Alicante.

Lorrio, A. J. 2010: "Los signa equitum celtibéricos: origen y evolución", Palaeohispanica 10, 427-446.

Lorrio, A. J. y Royo, J. I. 2013: "El guerrero celtibérico de Mosqueruela (Teruel): una pintura rupestre excepcional de la Edad del Hierro en el Alto Maestrazgo turolense", Antiquitas 25, 85-107.

Morales, F. y Jimeno, A. 1982: "Nuevas inscripciones romanas de la provincia de Soria", Celtiberia 63, 159-165.

Prósper, M. ${ }^{a}$ B. 2013-2014: “Time for Celtiberian dialectology: Celtiberian syllabic structure and the interpretation of the bronze tablet from Torrijo del 
Campo, Teruel (Spain)", Keltische Forschungen 6, 115-155.

Quesada, F. 2004: “¿Espejos de piedra? Las imágenes de armas en las estatuas de los guerreros llamados galaicos", Madrider Mitteilungen 44, 87-112.

Quesada, F. 2006: "Los celtíberos y la guerra: tácticas, cuerpos, efectivos y bajas. Un análisis a partir de la campaña del 153", F. Burillo (ed.), Segeda y su contexto histórico. Entre Catón y Nobilior (195 al 153), Zaragoza, 149-167.

Rodríguez, P. y Diez de Pinos, E. 2014: "Nueva inscripción celtibérica de El Pueyo de Belchite (Zaragoza)", Palaeohispanica 14, 245-262.

Romero Carnicero, F. 1976: Las cerámicas polícromas de Numancia, Soria.

Romero Carnicero, F. 1999: "El vaso de los guerreros de Numancia. Aproximación a su lectura iconográfica", Revista de Soria 25, 51-65.

Sanz Mínguez, C. 1997: Los vacceos, cultura y ritos funerarios de un pueblo prerromano en el valle medio del Duero. La necrópolis de Las Ruedas, Padilla de Duero (Valladolid), Valladolid.

Simón Cornago, I. 2007: "Muko · kaiko, relectura de K.9.1”. Palaeohispanica 7, 223-236.
Simón Cornago, I. 2013: Los soportes de la epigrafía paleohispánica. Inscripciones sobre piedra, bronce y cerámica, Zaragoza - Sevilla.

Simón Cornago, I. 2017: "Los jinetes de las estelas de Clunia”, Palaeohispanica 17, 383-406.

Simón Cornago, I. (en prensa): "El primer horizonte epigráfico de Clunia: promoción jurídica, latinización y memoria”, Epigraphica.

Taracena, B. 1954: "Los celtíberos: instituciones, armamento, indumentaria, religión y arte", R. Menéndez Pidal (dir.), Historia de España I.3, Madrid, 251-299.

Velaza, J. 2015: “La 'estela' celtibérica de Ibiza: consideraciones en torno a un epígrafe singular", Estudios de Lenguas y Epigrafía Antiguas 14, 373-385.

Wattenberg, F. 1963: Las cerámicas indígenas de Numancia, Madrid.

Recibido: 03-10-2016

Aceptado: 27-03-2017 